\title{
Strategic role of HRD in employee skill development: An employer perspective
}

\author{
Khalid Rasheed Memon \\ Department of Management Sciences,Experienced HR Professional and Mphil Student at Lahore Leads University, Lahore, Pakistan
}

Email address:

khalidilm@hotmail.com

To cite this article:

Khalid Rasheed Memon. Strategic Role of HRD in Employee Skill Development: An Employer Perspective. Journal of Human Resource Management. Vol. 2, No. 1, 2014, pp. 27-32. doi: 10.11648/j.jhrm.20140201.15

\begin{abstract}
Literature shows that an employee's skill development is dependent on its HR Department, especially in today's dynamic and uncertain environment, it is very important that HRD activities should be carried out in the organization while paving the way for future sustainability and to cope with the challenges / competition of global arena. In this regards, HRD role could be effective only if the employer is interested to invest on employee skill development. What exactly is employer's perspective is the motive of this paper to be explored while focusing Pakistani Manufacturing Industry included in KSE-100 Index. The paper is based on presenting the employers' perspective through secondary data of 20 manufacturing units of Pakistan from KSE-100 index; though, theoretical view has also been organized. Strategic role of HRD, employee skill development, employer perspective generally and then focusing Pakistani employers through literature insights are argued thoroughly. However, interconnection between HRD's role and employee skill development and employer has been the focus of this paper while highlighting its importance and effect. Moreover, the behavior and attitude of Pakistani Employer has been discussed practically while showing the current behavior and needs for improvement on investing on employees. Additionally, Employer's perspective hasn't been discussed earlier in the literature, especially focusing Pakistani Industry which opens new horizon for researchers to focus, an emerging market of developing country.
\end{abstract}

Keywords: Strategic HRD, Employee Skill Development, Sustainability, Human Capital

\section{Introduction}

World doesn't remain the same every day. It keeps on changing. Every day, we come across new developments which may be technological, process improvements, newer ideas, products and so on and thus business environment is facing considerable changes (Heraty, 1999)

Each employer wants to maximize his profit but profits margins are decreasing day by day specially in a developing country like Pakistan where we are having lesser governmental support for the industrial development, infrastructure and its necessities (Shah, 2010). On the other hand, globalization is another problematic area for a number of industries in such a developing country due to increased competition with regards to the product quality, services, price, delivery etc and thus organizations require to learn more quickly than competitors to remain distinctive and sustainable (Garavan, 2002).

How to meet both ends is the today's biggest challenge, which Pakistani Industry is facing and looking for some reliever so as to make optimal utilization of its resources with the available facilities and governmental support.

Organization is nothing but group of people working to achieve some predefined cause and mission; therefore, these are the people who need organizational focus to build their skills and capabilities to enable organizational for coping with the challenges of globalization and lesser support. People run machines, not machines run people so investment on people gives you productivity (Becker, 1994). These are the people who will generate ideas, techniques and tactics to get rid of such worse situation. And according to the Alfred Marshall (1890) "the most valuable of all capital is that invested in human beings" (Nerdrum, 2001) and here comes the role of Strategic Human Resource Development, as the development of skills is the task of HRD in an organization. Now a days, HRD professionals are assigned tasks to guide organizations with future focused strategic planning initiatives to create projections on the size, composition, and skill level of the workforce (Bartlett, 2006).

For instance, Pakistani Automotive industry has been an active and growing field in Pakistan for a long time, 
however not as much established to figure in the prominent list of the top automotive industries. Despite significant production volumes, transfer of technology and localization of vehicle components remains low. In Pakistan's context there are 10 cars in 1,000 persons which is one of the lowest in the emerging economies which itself speaks of high potential of growth in the auto sector and more so in the car production. We assume that all of the same, due to fact that our local employees lack those particular skills, although there are other many factors as mentioned above like Government support and infrastructure.

This particular research paper would focus on the role and contribution of HRD for the skills' development of an organization and the perspective of employer that how much he is agreed to invest on its employees, in today's competitive environment specially focusing on Pakistani Manufacturing Industry.

\section{Literature Review}

\subsection{The Concept of Human Capital}

The concept of human capital is not a new one. It was proposed by Schultz (1961) and later on expanded extensively by Becker (1964) based on his research of return-on-investment. Even later on Becker gave the wordings of 'general' and 'specific' human capital (Teixeira, 2002, Waldman, 2003) that are widely used by Human Resource Development Practitioners worldwide.

Human Capital theory is defined by Schultz (1961) as "the knowledge and skills that people acquire through education and training being a form of capital and that this capital is a product of deliberate investment that yields returns (Nafukho, 2004).

Becker (1993) defines it as "theory of human as investment in an individual's education and training which is similar to business investments in equipment". He looks at the economic effects of investment in education on employment and earnings and shows how the theory measures the incentive for such investment (Nafukho, 2004).

According to the theory, the amount spent on training \& development, education, healthcare etc are investments in capital which are being made on human. This training and education provided surely enriches his knowledge and skills which ultimately escalates his value as well as his future income (Becker, 1994). He conveys that human capital is a means of production into which additional investment yields additional output.

Human capital has always been the source of any organization, society or nation's growth and development and their mental and physical capacities are considered as worthwhile and prolific economic agent (Nerdrum, 2001). The Human Capital view of people is based more on an economic perspective. Human Capital perspective views people as a valuable asset rather than merely as a cost. Assets are those things that bring long term value to an organization. When viewed this way, it is easy to think of people and/or what they accomplish as adding long term value to an organization. "Only when the right employees are on board and are provided the training, tools, structures, incentives, and accountability to work effectively is organizational success possible (GAO , 1999). Moreover, human capital is strategic asset which should be enhanced instead of considering it as cost and thus its planning must be integral part of organizational strategic planning (GAO, 1999).

The resource based view of organization represents organization as collection of competencies, knowledge accumulation and experience (Wheelen, 2009). Moreover, if organizations want to remain competitive and sustainable then the only way is through skills' development and continuous learning and the people are the reason for an organization's sustainability; however, the firm must be careful regarding their products to be imitable make it non-substitutable to prevent rivals from replicating the value of the resources and competing away their benefits (Dyer, 2004). Firms make their human resources as competitive advantage through sequence of activities which involve the searching, selecting and hiring of efficient\& productive employees, they may be like raw material; investing on their development for the firm specific tasks and then by deploying them for the organization's benefit and use (Dyer, 2004) but they must be prevented from rivals for being whipped. Dyer (2004) quotes Klein \& Mahoney (1978) and Pandian (1992) that human capital can be inimitable if they are trained firm-specifically as your rivals can't use them in the same way.

\subsection{Strategic Human Resource Development (HRD)}

Human Resource Development has always served the needs of the organization especially on the critical business issues, technological changes and gaps in skills of employees were always catered by HRD function (R.A, 1995) but today's dynamic environment requires more from HRD i.e. to shape business strategy (R.A, 1995). This concept has been discussed in detail by Mikko Luoma (2000) in his article "Investigating the Link between strategy and HRD" that it is common view to consider HRD as the assessor of skills needs. As the organizations have division of labor on the basis of roles and competencies, therefore when organization fails to achieve its goals through existing competencies; skill competency gap arises which can only be filled through HRD. He further adds that HRD becomes strategic when its helps organization to achieve its objectives while paving the way towards its destination through its rational, deliberate and sequential process of assessing the needs till evaluation of outcomes in the form learning and improvement. However, it's strategic in nature as organization's strategy will be on stake till it is being taken care of. (Luoma, 2000).

This concept of Luoma (2000) has been strengthened by Ida Wognum and Jo Fond Lam (2000) in this way: "The word 'strategic' emphasizes the company perspective and connects the link between HRD and the organizational goals and objectives. Strategic aligning then concerns the development of HRD goals and objectives and HRD interventions, which are aligned with company strategy, problems, and developments" (Lam, 2000). According to 
Martin McCracken and Marry Wallace (2000) Strategic $\mathrm{HRD}$ is proactive and system-wide intervention that is always linked to strategic planning process otherwise it would be reactionary like traditional training and development activities (Wallace, 2000). Further the authors have mentioned the nine characteristics of strategic HRD given by Garavan (1991) in which "Integration with organizational missions and goals" is top of the list. The authors Martin McCracken and Marry Wallace (2000) have also conceptualized a new model for strategic HRD characteristics while classifying "shaping organizational missions and goals" at the top.

Donnell and Garavan (1997) emphasize that skills and knowledge of the workers are the critical factors that determine the growth of the economy while becoming strategic in nature. Therefore, training should be organizations mainstream function. Moreover, HRD should also be implicit part of strategic planning of the organization (Garavan, 1997).

\subsection{Role of Strategic HRD in Employee Skill Development}

HRD's role has become very much pivotal in identifying and recognizing employee deficiencies and skills' gap at the management level, as they are the key players and require more strategic focus and grooming (Wallace, 2000), through prediction of long term requirements of the organization, although it is tough but HRD does so through its future oriented strategic planning initiatives (Bartlett, 2006) aligned with the mission of the organization and the changes occurring within the organization's external environment (Lam, 2000).

According to Donnell and Garavan (1997) Skills are either inborn characteristic or acquired. If it is acquired skill is that it is learned (Garavan, 1997). As the acquired skills are learned through education and training in organization therefore, the training plan of the organization should aligned with the corporate strategy (Donnell, 1997). According to the authors there is a direct relationship between the quality of HRM, employee development and corporate success and thus this can be implemented through three human resource means: "first, through performance appraisal; second, through the development of employees' learning potential; and third, through balancing training for tasks with training for the development of the individual as a whole" (Donnell, 1997).

Garavan (1999) suggest that the methodology to be adopted in this learning process is dependent of the hierarchy level objectives; however "the appropriateness of a particular strategy depends on the age, intelligence, motivational background, achievement history and participant autonomy" (Garavan, 1999). The authors have focused and emphasized on the methods of "on the jobtraining" and mentoring as the popular and suitable methods for the management development. Moreover lectures, games, simulations, projects, case studies, experiential, guided reading, role playing, seminars and programmed instructions etc are likely to be more effective than formalized methods of learning (Garavan, 1999). Tacit knowledge is always difficult to share and learn without doing practical work but somehow may be learned through discussion, sharing of practices and cases in groups (Garavan, 2001). The authors suggest that competencies are not build at once. It obviously takes time to be developed and present the outcome therefore employees must be treated as permanent rather than contingent.

It should be noted as Garavan (2001) posits that the characteristics like emotions, attitude and cognitive originate are in-build and thus can't be learned; however, "competencies don't relate to capacities but instead to the willingness and the ability of the employee to utilize capacity in specific situation".

HRD organizes all these training activities; however, HRD trainers and professionals must keep in mind that HRD's role has become more dynamic and strategic in this fluctuating environment and thus HRD should be more innovative and consulting i.e. facing organization change issues, training and learning matters. They can contribute well in achieving organizational goals provided they act as leaders as well as facilitators of change (Wallace, 2000) and they should be proactive rather reactive (Tseng, 2008).

\section{Theoretical Framework}

This particular study proposes that "Strategic HRD" has positive and directly proportional relationship with "Employee Skill Development" while there is a mediating variable "Employer Investment" which affects directly on the activities of HRD and employee skill development process.

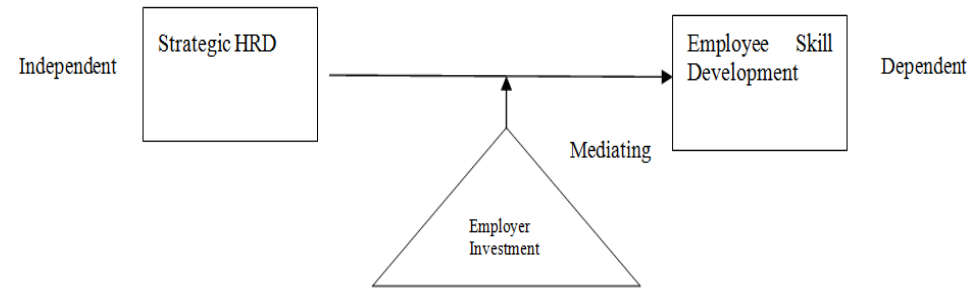

Fig 1. Relationship between HRD, Employee Skill Development and Employer Investment (Khalid Rasheed Memon, 2014)

The above diagram shows that "Strategic HRD" is Independent Variable whereas "Employee Skill Development" is dependent variable having dependency on HRD. More are the activities of HRD, more will be skill development. Moreover, the activities of HRD and whole of this process is being affected by "Employer Investment" which means that 
more is the investment from employer, more will be activities by HRD for employee skill development and thus if employer investment is less then there will be lesser employee skill development activities. It clearly means that if we want our human resources to be equipped with latest market oriented skills or having firm-specific skills then we'll have to strengthen our HRD where HRD can be forced by Employer through his willingness to invest on Human Resources while making them Asset for the organization.

\section{Employer's Perspective for HRD Activities}

Due to the increasing importance of Human Capital and its competencies required for the sustainability of the organization, the employers have started to provide job security, respect, investments for their grooming \& development and prosperity (Durkovic, 2009). In his article "Development of Human Resources as Strategic Factors of the Companies' Competitive Advantage" Durkovic (2009) has mentioned that now the successful global organization are putting more and more emphasis towards HRD activities and thus the organizations in America, Asia and Europe has achieved phenomenal growth and success by providing education to their employees.

Thomas. N. Garavan (1999) in an article "Management development: contemporary trends, issues and strategies" mentions that averagely $3 \%$ of the European Companies' payroll is spent on management development activities, which shows how much important it is for the employers. Moreover, organizations are looking for newer approaches towards leadership development and thus its budgets will continue to grow considerably during the coming century (McCarthy, 2007)

Ian Smith (2003) in his article "Continuing professional development and workplace learning 5: human resource development - a strategic imperative" says that skill development and learning activities are being planned at national level by the countries like UK, Australia and India and thus they have formulated policies and departments at national level.

\section{Employer's Perspective for HRD Activities in Pakistan}

\subsection{Design/Methodology}

While researching and gathering data, Secondary Data Collection Methodology and Tools were adopted and thus 20 manufacturing units of various industries of Pakistan from KSE-100 Index were searched particularly for this paper. Although the author has conducted the interviews of 2 HR Managers and 2 CEO's as well but Secondary Data Gathering Methodology has been dominant and focused accordingly.

Data gathering methodology was chosen to be based on Secondary Data due to the accuracy as well as convenience in gathering of data. Accuracy in a sense that Annual/Financial Reports are the published materials and are publicized for presenting the firm's performance, interest/activities as well as future intentions. Websites of these firms are another source of gathering published material and is considered as secondary data.

\subsection{Findings and Discussion}

Most of the firms were either found to be involved in "Training \& Development" activities or have recently started realizing the importance of training activities and thus they have started to develop In-House Training Plans as first step. On the other hand, few of them were also found be ignorant of this important aspect of human development.

For instance, as mentioned in the Annual Report of AlGhazi Tractors, they have developed their own In-House Training Centre for all kind of trades. Similarly, Rafhan Maize Products have provided in-house training of more than 15,000 hours in 2011 to its workers. These were 714 in-house training courses and were imparted to 8280 employees, whereas 49 personnel from Management Cadre participated in 20 different training sessions.

Ibrahim Fibres nominated 42 employees from Management Cadre in 2011 for external trainings inside the country and abroad. Bolan Casting has invested approx. Rs. 2 million in 2011 and up till now their training expenses are 1.26 million Rupees for 2012, as presented in their financial report. Similarly, Attock Cement, Sitara Chemicals, Pakistan Cables, Ittehad Chemicals etc have also mentioned briefly about their training activities and thus are increasing their training budgets gradually.

During an interview with HR Manager of Millat Tractors, Mr. Shahzad said that they focus more towards management training rather than operational staff's training. They do give on-job training to their operational/tactical level staff. Similarly, HR Manager of Ittehad Chemicals also emphasized the increasing need of training budget and said that their budgets have improved drastically with regards to the amounts kept in budgets of previous years and they are using external as well as internal training methods for equipping their employees with the required skills, however, still they are long way behind others.

Other bigger names in Pakistani Industry which are worth mentioning and have realized the true value of training have formal training setups and budgets shown throw their financial statements and annual reports. For instance, Fatima Fertilizer provided 50,000 hours training to different cadres of management and workers in 2011. Similarly, Atlas Honda Pakistan spent Rs. 2.66 million in 2009 for training activities.

From the above facts and figures, it can be said that even without Governmental Support and Infrastructure, the employers of Manufacturing Units belonging from various industries of Pakistan have finally realized the role of training \& development activities and considered it valuable and differentiating factor for the uplift of 
corporate image and stake holders satisfaction. Thus, they have changed their traditional mindset and started investing on the adoption of newer techniques and methodologies.

Moreover, those organizations whose financials didn't proved their investments on employee skill development have shown intention and determination to carryout training \& development activities while giving due focus on this huge neglected area.

Apart from the above factual data, earlier Pakistan was facing serious problems of slow growth, lesser exports and loss of outputs due to continuous carelessness towards Human Resource Development activities. Kemal (2005) presents Wagner's argument that "vocational and professional training system could have a major impact on national competitiveness", but vocational training and technical education was introduced in the country in the year 1999 whereas Pakistan came into being in 1947 (Shah, 2010). Finally, it is stated that, there is lesser business linkage between training institutes and corporate sector which is required to be developed for the prosperity and betterment of the country (Shah, 2010). Even the linkage between the Academia and Industry is very poor.

\section{Implications for Researchers and Recommendations}

Based on the literature review, it may be identified that research at organizational level hasn't been conducted specifically for measuring the role of HRD in employees' skills development in Pakistan.

Therefore, there is strong need to carry out an empirical research focusing the above issues which will surely open new horizons for the international research community and HRD professionals. However:

1. Researchers avoid assuming that HRD in a developing country may not be challenging enough. In fact, it might be the contrary and enhance one's current HRD perspectives, thereby opening more avenues for HRD research and practice.

2. The international HRD community should consider creating collaborative partnerships with public and private HRD institutions in South Asia, particularly in Pakistan. Starting exchange programs, organizing field trips for HRD students, and teaching and conducting research at educational institutions are some of the steps that can be taken to promote collaboration with institutions in Pakistan.

\section{References}

[1] Becker, G. S., 1994. Human Capital: A Theoretical and Empirical Analysis with Special Reference to Education. The University of Chicago Press.

[2] Chien-Chi, T, Gary. N. M, 2008. Strategic HRD practices as key factors in organizational learning. Journal of European Industrial Training , 418-432.
[3] David O’Donnell, Thomas. N., 1997. Viewpoint: Linking training policy and practice to organizational goals. Journal of European Industrial Training, 301-309.

[4] Dyer, N. W., 2004. Human Capital and Learning as a Source of Sustainable Competitive Advantage. Strategic Management Journal , 1155-1178.

[5] Fredrick M. N, Nancy. H. Kit, B., 2004. Human Capital Theory: implications for human resource development. Human Resource Development International, 545-551.

[6] GAO., 1999. Major Management Challenges and Program Risks: A Government wide perspective. Washington D.C: United States General Accounting Office.

[7] Garavan, T.N, David, O., 1997. New perspectives on skill, learning and training: a viewpoint. Journal of European Industrial Training, 131-137.

[8] Iftikhar, H. S, Muhammad. A, Fazulur. R., 2010. Structure of Technical Education and Vocational Training in Pakistan. Journal of Technical Education and Training, 63-75.

[9] Iftikhar, H. S, 2011. Situational Analysis of Vocational of Technical Education in Pakistan. Journal of Technical Education and Training, 53-62.

[10] Kemal, A. R., 2005. Skill Development in Pakistan. The Pakistan Development Review , 349-357.

[11] Kenneth, B., Karren. J and Ingrid, E. S, 2006. A Comparative Study of Strategic HRD Approaches for Workforce Planning in the Tourism Industry. Minnesota.

[12] Lam, I. W., 2000. Stakeholder involvement in strategic HRD aligning: the impact on HRD effectiveness. International Journal of Training and Development, 98-110.

[13] Luoma, M., 2000. Investigating the link between strategy and HRD. Personnel Review, 769-790.

[14] Nerdrum, L., 2001. Intellectual Capital: a human capital perspective. Journal of Intellectual Capital , 127-135.

[15] Noreen, H., Micheal. J. M, 1999. Human Resource Development in Ireland: Organizational Level Evidence. Journal of European Industrial Training , 21-33.

[16] Torroco, R. J, SwansonR. A, 1995.The Strategic Roles of Human Resource Development. Human Resource Planning, 10-21

[17] Sultan, A. A, Abdul, G. Abdul, M. N, 2005. Investigations into the Human Resource Development Status and its Impact on Farm Output in Rural Areas of District Jhang, Pakistan. Journalof Agriculture\& Social Sciences , 10-13.

[18] Thomas L. W., J. D., 2009. Concepts in Strategic Management and Business Policy. Prentice Hall.

[19] Thomas, N. G., Bridie. B, Fiachra, O, 1999. Management Development: contemporary trends, issues and strategies. Journal of European Industrial Training , 191-207.

[20] Thomas, N. G., Micheal. M, Patrick, G. Eammon, C., 2001. Human Capital Accumulation: the role of Human Resource Development. Jounal of European Industrial Training , 4868.

[21] Aurora T., 2002. On The Link Between Human Capitaland Firm Performance. Portugal: FEP . 
[22] Thomas, N. G., P, C. N, H.,1995. The emergnence of strategic Human Resource Development. Journal of European Industrial Training , 4-10.

[23] Thomas, N. G., Micheal. M, Patrick, G. David, M.,2002. Human Resource Development and workplace learning: emerging theoritical perspectives and organizational practices. Journal of European Industrial Training, 60-71.

[24] Waldman, R. G., 2003. Task Specific Human Capital. Task Specific Human Capital . AEA Papers and Proceedings.

[25] Wallace, M. M., 2000. Towards a redefination of strategic HRD. Journal of European Industrail Training , 281-290.

[26] Geraldine, O, John, E.T., 1999. The development of Irish HRD professionals in comparison with European professionals: roles, outputs and competencies. International Journal of Training and Development, 250-268
[27] T. V. R, Raju. R and Taru. Y., 2007. A Study of HRD Concepts, Structure of HRD Departments and HRD Practices in India. Vikalpa, 49-63

[28] Jelena, V. Đ., 2009. Development of Human Resources as Strategic Factors of the Companies' Competitive Advantage. Economics and Organization, $59-67$

[29] Alma, M. M, Thomas, N. G., 2007. Understanding acceptance of multisource feedback for management development. Personnel Review, 903 - 917.

[30] Ian, S., 2003. Continuing professional development and workplace learning 5: human resource development - a strategic imperative. Library Management, $443-445$ 